\title{
Determination of Haematological Changes Associated with Syphilis in Subjects in Umudike, Abia State, Nigeria
}

\author{
Emmanuel Ifeanyi Obeagu' ${ }^{1 *}$, Obioma Azuonwu² ${ }^{2}$ Blessing Chimezie Didia ${ }^{3}$, Getrude Uzoma Obeagu ${ }^{4}$ and Florence \\ Onyenweaku ${ }^{1}$
}

${ }^{1}$ Department of Health Services, Michael Okpara University of Agriculture, Nigeria

${ }^{2}$ Department of Medical Laboratory Science, Rivers State University, Nigeria

${ }^{3}$ Department of Medicine and Surgery, Rivers State University, Nigeria

${ }^{4}$ Department of Nursing Science, Ebonyi State University, Nigeria

*Corresponding author: Emmanuel Ifeanyi Obeagu, Department of Health Services, Michael Okpara University of Agriculture, Umudike, Abia State, Nigeria

Submission: 海January 12, 2018; Published: 監January 29, 2018

\begin{abstract}
Sexual transmitted diseases (STDs) are increasing. The prevalence of syphilis is increasing especially as Human Immunodeficiency virus (HIV) is increasing. There is paucity of published researches on haematological changes associated to syphilis in this part of the World. The population of the University where this study was done is dominated with highly sexually active persons. The study was done to determine haematological changes associated to syphilis in the subjects in Umudike. The study was done in a Secondary Health Institution. The study started January 2015 to December 2016. A total of seventy subjects ( 37 females, 33 males) were recruited for the study. Twenty (20) subjects ( 12 females, 8 males) were syphilis patients aged 20- 38 years and fifty (50) subjects ( 25 females, 25 males) were the apparently healthy individuals aged matched with the patients. About $2 \mathrm{ml}$ of venous blood sample was collected from each participant into EDTA anticoagulated container following aseptic techniques. The plasma was used for the diagnosis. A rapid diagnostic test kits were used for the diagnosis of syphilis from each sample. Haematological investigation was done using Mindray $\mathrm{BC}-5300$. The results were presented in tables as mean and standard deviation and student t-test used for analysis and the level of significance was set at $\mathrm{P}<0.05$. The results showed significant decrease $(\mathrm{P}<0.05)$ in the $\mathrm{WBC}$, neutrophil, $\mathrm{RBC}$, Haemoglobin, $\mathrm{PCV}, \mathrm{MCV}, \mathrm{MCH}$ and $\mathrm{MCHC}$ of the syphilis subjects $\left(4.5 \pm 0.6 \times 10^{9} / \mathrm{L}, 50.0 \pm 8.6 \%, 4.7 \pm 0.3 \times 10^{12} / \mathrm{L}, 14.0 \pm 0.5 \mathrm{~g} / \mathrm{dl}, 42.0 \pm 3.2 \%, 89.9 \pm 10.6 \mathrm{fl}, 29.9 \pm 5.6 \mathrm{pg}, 333.3 \pm 14.2 \mathrm{~g} / \mathrm{l}\right)$ compared to the control $\left(5.6 \pm 0.8 \times 10^{9} / \mathrm{L}, 68.2 \pm 10.4 \%, 5.1 \pm 0.7 \mathrm{X} 10^{12} / \mathrm{L}, 15.4 \pm 0.8 \mathrm{~g} / \mathrm{dl}, 46.2 \pm 4.1 \%, 90.1 \pm 12.1 \mathrm{fl}, 31.0 \pm 3.7 \mathrm{pg}, 337.0 \pm 20.6 \mathrm{~g} / \mathrm{l}\right)$, significant increase (P<0.05) in the lymphocyte, monocyte of the syphilis subjects $(47.0 \pm 5.2 \%, 2.0 \pm 0.1 \%)$ compared to the control $(30.6 \pm 7.2 \%, 1.0 \pm 0.1 \%)$ and no significant difference in basophil and MCV of the syphilis subjects $(0.1 \pm 0.1 \%, 89.9 \pm 10.6 \mathrm{pg})$ compared to the control $(0.1 \pm 0.1 \%, 90.1 \pm 12.1 \mathrm{~g} / \mathrm{l})$.From the study, it can be shown that syphilis disrupts haematopoiesis. The infection altered the haematological parameters studied. The bone marrow activity might be reduced as seen in all the cell line. Prompt diagnosis and treatment is expedient to avert the danger that might be caused to the haematological parameters which will in turn affect both reproductive ability and vitality of life generally.
\end{abstract}

Keywords: Haematological changes; Syphilis; Umudike

\section{Introduction}

Syphilis has been reported as a sexually transmitted infection linked to bacterium Treponema pallidum. The manifestation of syphilis varies depending in which of the four stages it presents [1]. Syphilis is most commonly spread through activity. It believed to be transmitted from mother to baby during pregnancy or at birth, resulting in congenital syphilis [2]. The risk of sexual transmission of syphilis can be reduced by using a latex condom [1]. Syphilis can be effectively treated with antibiotics. It is strongly agreed that the preferred antibiotic for most cases is benzathine penicillin $G$ injected into a muscle. In those who have a severe penicillin allergy, doxycycline or tetracycline may be used. It has been shown in those with neurosyphilis, intravenous penicillin G potassium or ceftriaxone is recommended. It was strongly reported that during treatment people may develop fever, headache, and muscle pains, a reaction known as Jarisch-Herxheimer [1].

Report has shown that 2015, about 45.4 million people were infected with syphilis [3], with 6 million new cases [4]. During 2015, it caused about 107,000 deaths, down from 202,000 in 1990 [5,6]. After decreasing dramatically with the availability of penicillin in the 1940s, rates of infection have increased since the turn of the millennium in many countries, often in combination with human immunodeficiency virus $[7,8]$. This is believed to be partly due to increased promiscuity, prostitution, decreasing use of condoms, and unsafe sexual practices among men who have sex with men [9- 
11]. It is believed that syphilis is spread mainly by sexual contact or during pregnancy from a mother to her fetus; the bacteria is able to pass through intact mucous membranes or compromised skin [12]. Nonetheless, it is can be passed by kissing near a lesion, as well as oral, vaginal, and anal sex [7]. About $30 \%$ to $60 \%$ of those exposed to primary or secondary syphilis will get the disease [13]. Syphilis can be transmitted by blood products, but the risk is low due to blood testing in many countries.

\section{Aim}

The study was done to determine haematological changes associated with syphilis in subjects in Umudike.

\section{Materials and Methods}

\section{Study area}

The study was conducted in the Department of Health Services, Michaela Okpara University of Agriculture, Umudike, Abia State, Nigeria.

\section{Subjects}

A total of seventy subjects (37 females, 33 males) were recruited for the study. Twenty (20) subjects (12 females, 8 males) were syphilis patients aged 20 - 38 years and fifty (50) subjects $(25$ females, 25 males) were the apparently healthy individuals aged matched with the patients.

\section{Sample collection}

About $2 \mathrm{ml}$ of venous blood sample was collected from each participant into EDTA anticoagulated container following aseptic techniques. The plasma was used for the diagnosis of syphilis using VDRL test and the whole blood used for full blood count test.

\section{Laboratory investigation}

VDRL: A rapid diagnostic test kits were used for the diagnosis of syphilis from each sample.

Haemtological investigation: Haematological investigation was done using Mindray BC-5300. The parameters investigated include white blood cell, neutrophil, lymphocyte, monocyte, eosinophil, basophil, red blood cell, haemoglobin, packed cell volume, mean cell volume, mean cell haemoglobin and mean cell haemoglobin concentration

Ethical consideration: Ethical approval was gotten from the relevant health agencies that are directly involved to grant approval, also informed consents were obtained from the subjects and confidentiality of the results ensured throughout the period of the study till date.

Statistical analysis: The results were presented in tables as mean and standard deviation and student t-test used for analysis and the level of significance was set at $\mathrm{P}<0.05$

\section{Results}

The results showed significant decrease $(\mathrm{P}<0.05)$ in the $\mathrm{WBC}$, neutrophil, RBC, Haemoglobin, PCV, MCV, MCH and MCHC of the syphilis subjects $\left(4.5 \pm 0.6 \times 10^{9} / \mathrm{L}, 50.0 \pm 8.6 \%, 4.7 \pm 0.3 \times 10^{12} / \mathrm{L}\right.$, $14.0 \pm 0.5 \mathrm{~g} / \mathrm{dl}, 42.0 \pm 3.2 \%, 89.9 \pm 10.6 \mathrm{fl}, 29.9 \pm 5.6 \mathrm{pg}, 333.3 \pm 14.2 \mathrm{~g} / \mathrm{l})$ compared to the control $\left(5.6 \pm 0.8 \times 10^{9} / \mathrm{L}, 68.2 \pm 10.4 \%\right.$, $5.1 \pm 0.7 \times 10^{12} / \mathrm{L}, 15.4 \pm 0.8 \mathrm{~g} / \mathrm{dl}, 46.2 \pm 4.1 \%, 90.1 \pm 12.1 \mathrm{fl}, 31.0 \pm 3.7 \mathrm{pg}$, $337.0 \pm 20.6 \mathrm{~g} / \mathrm{l})$, significant increase $(\mathrm{P}<0.05)$ in the lymphocyte, monocyte of the syphilis subjects $(47.0 \pm 5.2 \%, 2.0 \pm 0.1 \%)$ compared to the control $(30.6 \pm 7.2 \%, 1.0 \pm 0.1 \%)$ and no significant difference in basophil and MCV of the syphilis subjects $(0.1 \pm 0.1 \%$, $89.9 \pm 10.6 \mathrm{pg})$ compared to the control $(0.1 \pm 0.1 \%, 90.1 \pm 12.1 \mathrm{~g} / \mathrm{l})$ (Table 1) (Figure 1-3).

Table 1: Showing haematological markers of syphilis subjects and the control.

\begin{tabular}{|c|c|c|c|c|}
\hline Parameters & Syphilis (20) & Control (50) & P-Value & Level of Significance \\
\hline WBC $\left(X 10^{9} / \mathrm{L}\right)$ & $4.5 \pm 0.6$ & $5.6 \pm 0.8$ & 5.14 & $\mathrm{P}<0.05$ \\
\hline Neutrophil (\%) & $50.0 \pm 8.6$ & $68.2 \pm 10.4$ & 22.78 & $\mathrm{P}<0.05$ \\
\hline Lymphocyte (\%) & $47.0 \pm 5.2$ & $30.6 \pm 7.2$ & 25.79 & $\mathrm{P}<0.05$ \\
\hline Monocyte (\%) & $2.0 \pm 0.1$ & $1.0 \pm 0.1$ & 11.95 & $\mathrm{P}<0.05$ \\
\hline Eosinphil (\%) & $1.0 \pm 0.1$ & $0.1 \pm 0.1$ & 0.05 \\
\hline Basophil (\%) & $0.1 \pm 0.1$ & $0.1 \pm 0.1$ & 2.35 & $\mathrm{P}>0.05$ \\
\hline RBC (X1012/L) & $4.7 \pm 0.3$ & $5.1 \pm 0.7$ & 6.93 & $\mathrm{P}<0.05$ \\
\hline Haemoglobin (g/dl) & $14.0 \pm 0.5$ & $15.4 \pm 0.8$ & 8.54 & $\mathrm{P}<0.05$ \\
\hline PCV (\%) & $42.0 \pm 3.2$ & $46.2 \pm 4.1$ & 0.23 & $\mathrm{P}<0.05$ \\
\hline MCV (fl) & $89.9 \pm 10.6$ & $90.1 \pm 12.1$ & 1.85 & $\mathrm{P}>0.05$ \\
\hline MCH (pg) & $29.9 \pm 5.6$ & $31.0 \pm 3.7$ & 3.49 & $\mathrm{P}<0.05$ \\
\hline MCHC (g/l) & $333.3 \pm 14.2$ & $337.0 \pm 20.6$ & & \\
\hline
\end{tabular}

WBC: Total White Cell Count; RBC: Red Blood Cell; PCV: Packed Cell Volume, MCV: Mean Cell Volume; MCH: Mean Cell Haemoglobin; MCHC: Mean Cell Haemoglobin Concentration 


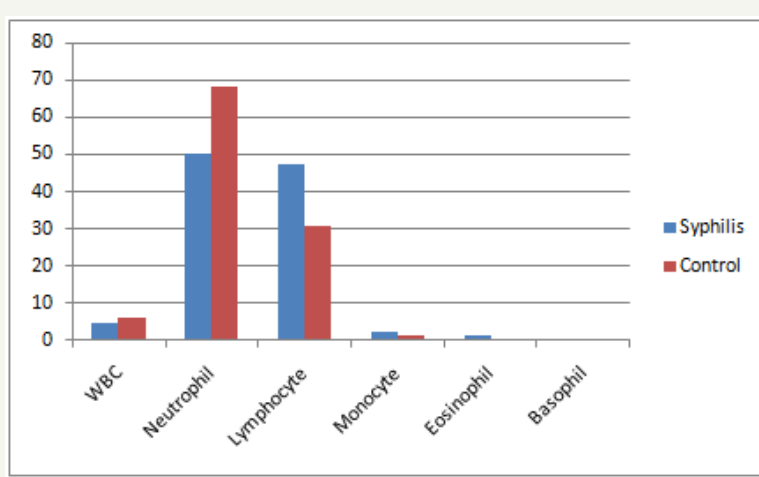

Figure 1: Showing WBC, Neutophil, Lymphocyte, Monocyte, Eosinophil, Basophil of the subjects.

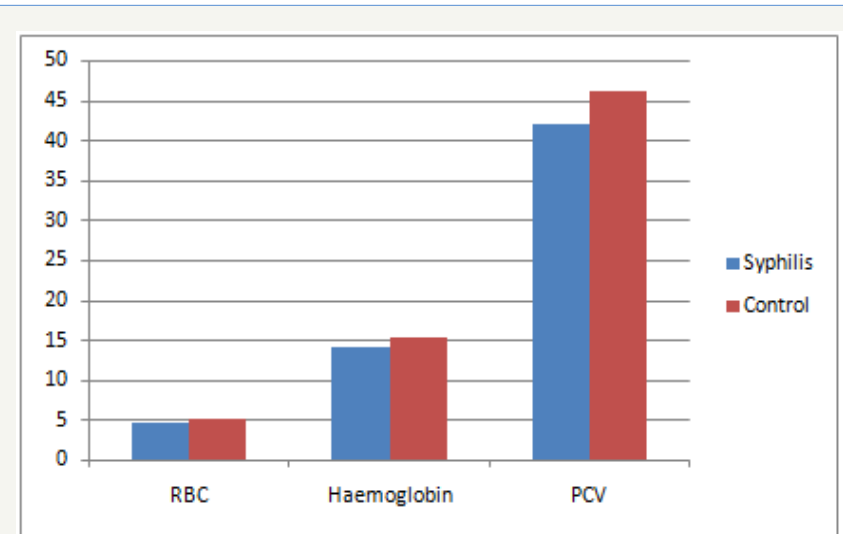

Figure 2: Showing RBC, Haemoglobin and PCV of the subjects.

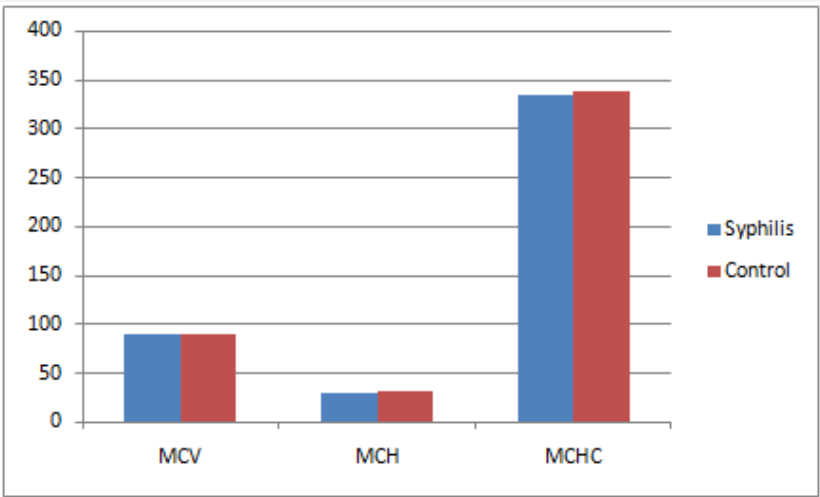

Figure 3: Showing $\mathrm{MCV}, \mathrm{MCH}$ and $\mathrm{MCHC}$ of the subjects.

\section{Discussion}

The study showed significant changes in the whole haematological parameters studied except the basophil and MCV. The study showed suppression in WBC, neutrophil, RBC, haemoglobin, $\mathrm{PCV}, \mathrm{MCH}$, and $\mathrm{MCHC}$ and elevation in lymphocyte and monocyte of the syphilis subject compared to the control. It could be as result of suppressed bone marrow activity. The increased lymphocyte and monocyte may induce increased release of cytokines which will affect the treatment course. The cytokines can affect the pathogenesis and the prognosis of the treatment. It was reported that the striking clinical changes of early congenital syphilis include rash, severe rhinitis, moist lesions at mucocutaneous junctions, painful limbs, lymphadenopathy, and hepatosplenomegaly. Jaundice is common, as is hypoproteinaemia which may cause oedema. Of the haematological findings, anaemia commonly occurs [14]. The incidence of thrombocytopenia is not clear, although the association of increased platelet turnover (with or without thrombocytopenia) with syphilis is well known [15]. The study shows that the haematological abnormalities may sometimes be severe.

Haematological parameters should be carefully monitored in the patients suffering from syphilis. Information on the haematological changes in syphilis patients is scarce in this part of the World. It is important to carry out this research in this University dominated with highly active sexual individuals. Syphilis is known to be one of the sexual transmitted diseases (STDs). It has been shown that sexual transmitted diseases are increasing each day. It is important to find out what this infection could cause to the haematological system. Haematological tests are good indicators of health and disease state. It is one of the measures of prognosis for treatment. This study shows that syphilis infection alter haematological parameters. This will help in diagnosis and treatment of patients.

\section{Conclusion}

This study shows that syphilis has a suppressive effect on the haematopoiesis which lead to reduced level of the haematological parameters studied in the syphilis subjects. It has been shown to have suppressive effect on the bone marrow and may result to pancytopaenia. Early diagnosis and treatment is advocated.

\section{References}

1. CDC (2015) Syphilis - CDC Fact Sheet.

2. Woods CR (2009) Congenital syphilis-persisting pestilence. Pediatr Infect Dis J 28(6): 536-537.

3. GBD (2015) Disease and Injury Incidence and Prevalence, Collaborators (2016) Global, regional, and national incidence, prevalence, and years lived with disability for 310 diseases and injuries, 1990-2015: a systematic analysis for the Global Burden of Disease Study 2015. Lancet 388(10053): 1545-1602.

4. Newman L, Rowley J, Vander Hoorn S, Wijesooriya NS, Unemo M, et al. (2015) Global Estimates of the Prevalence and Incidence of Four Curable Sexually Transmitted Infections in 2012 Based on Systematic Review and Global Reporting. PLoS One 10(12): e0143304.

5. Lozano R, Naghavi M, Foreman K, Lim S, Shibuya K, et al. (2012) Global and regional mortality from 235 causes of death for 20 age groups in 1990 and 2010: a systematic analysis for the Global Burden of Disease Study 2010. Lancet 380(9859): 2095-2128.

6. GBD (2015) Mortality and Causes of Death, Collaborators (2016) Global, regional, and national life expectancy, all-cause mortality, and cause-specific mortality for 249 causes of death, 1980-2015: a systematic analysis for the Global Burden of Disease Study 2015. Lancet 388(10053): 1459-1544.

7. Kent ME, Romanelli F (2008) Reexamining syphilis: an update on epidemiology, clinical manifestations, and management. Ann Pharmacother 42(2): 226-236.

8. Franzen C (2008) Syphilis in composers and musicians--Mozart, Beethoven, Paganini, Schubert, Schumann, Smetana. Eur J Clin Microbiol Infect Dis 27(12): 1151-1157. 
9. Coffin LS, Newberry A, Hagan H, Cleland CM, Des Jarlais DC, et al. (2010) Syphilis in Drug Users in Low and Middle Income Countries. Int J Drug Policy 21(1): 20-27.

10. Gao L, Zhang L, Jin Q (2009) Meta-analysis: prevalence of HIV infection and syphilis among MSM in China. Sex Transm Infect 85(5): 354-358.

11. Karp G, Schlaeffer F, Jotkowitz A, Riesenberg K (2009) Syphilis and HIV co-infection. European journal of internal medicine 20(1): 9-13.

12. Stamm LV (2010) Global challenge of antibiotic-resistant Treponema pallidum. Antimicrob Agents Chemother 54(2): 583-589.

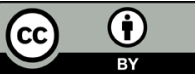

Creative Commons Attribution 4.0

International License

For possible submission use the below is the URL
13. Bhatti MT (2007) Optic neuropathy from viruses and spirochetes. Int Ophthalmol Clin 47(4): 37-66.

14. Hira SK, Bhat GJ, Patel JB, Din SN, Attili RV, (1985) Early congenital syphilis: clinico radiologic features in 202 patients Sex Transm Dis 12(4): 177-183.

15. Stockman JA (1981) Hematologic manifestation of systemic diseases. In: Nathan DG, Oski FA (Eds.), Hematology of infancy and childhood. Philadelpha: WB Saunders, USA, pp. 1339-1387.

Your subsequent submission with Crimson Publishers will attain the below benefits

- High-level peer review and editorial services

- Freely accessible online immediately upon publication

- Authors retain the copyright to their work

- Licensing it under a Creative Commons license

- Visibility through different online platforms

- Global attainment for your research

- Article availability in different formats (Pdf, E-pub, Full Text)

- Endless customer service

- Reasonable Membership services

- Reprints availability upon request

- One step article tracking system 